\title{
A two level probabilistic inventory model with a constraint on holding cost
}

\author{
M. Nagasree ${ }^{1 *}$, M. Madhavilata ${ }^{2}$ and A. Sailakumari ${ }^{3}$
}

\begin{abstract}
In this paper a single period two level probabilistic inventory model with continuous distribution of demand is considered. The objective of this paper is to find the optimal purchase quantity $S^{\star}$ and also the quantity that can be stored in $\mathrm{OW} \mathrm{W}^{\star}$ which minimizes the expected total cost for the period under the restriction that the expected holding cost cannot exceed fixed quantity. Lagrange's method of multipliers approach is used to find the optimal values of $S^{\star}$ and $\mathbf{W}^{\star}$. Numerical example is illustrated to represent the model
\end{abstract}

Keywords

Continuous distribution, Lagrange's method of multipliers, Probabilistic inventory model.

AMS Subject Classification

90B05.

${ }^{1}$ Research Scholar, Department of Mathematics, Jawaherlal Nehru Technological University Anantapur, Anatapuramu, India;

${ }^{2}$ Sr.Assistant Professor,Department of Humanities and Mathematics, G.Narayanamma Institute of Technology and Science for women, Hyderabad, India;

${ }^{3}$ Assistant Professor, Department of Mathematics, Jawaherlal Nehru Technological University Anantapur, Anatapuramu, India *Corresponding author: ${ }^{*}$ nagasree@gnits.ac.in; ${ }^{2}$ madgnits@gmail.com; ${ }^{3}$ asailakumari@gmail.com

Article History: Received 22 November 2018; Accepted 09 May 2019

(C) 2019 MJM

\section{Contents}

1 Introduction .224

Literature Review

224

3 Assumptions ........................... 225

4 Notations ................................ 225

Model Description.........................225

6 Example............................... 226

7 Conclusions...........................226

References ............................. 226

\section{Introduction}

Many researchers consider a deterministic demand but in practical the demand is uncertain.If the demand is uncertain, it is difficult to maintain an inventory. In the examples like News papers and seasonal products demand cannot be determined. By considering the average demand a suitable probability distribution function can be selected and the expected cost can be calculated. In the paper, [1] explained a single period probabilistic demand when the order is for only one period which cannot be transferred to the next period.
It is a general practice that $\mathrm{OW}$ has a fixed capacity $\mathrm{W}$ and RW has infinite capacity. The purchased quantity is first stored in OW and the remaining in RW. An attempt is made to vary both the quantities in RW and OW. The objective of the paper is to find optimal number of units that can be stored in both RW and OW. By considering probabilistic demand and also imposing a constraint on the holding cost the total expected cost is calculated. Lagrange's method of multipliers and Newton Raphson Method are used to find the solution. It is illustrated numerically by an example.

\section{Literature Review}

Many papers are published on two level inventory models with deterministic demand by considering the various patterns stock dependent demand with permissible delay in payment was taken by [2] and [3] considered exponentially increasing demand, [4]considered demand with price sensitive, [5] developed a model with ramp type demand and weibull deterioration, while [6] considered the power demand pattern, [7] has dealt time dependent demand under inflation.

A two level of inventory model with probabilistic demand and uniform demand is considered by [8] and discussed when the inventory is dependent on time and also with a constant age specific rate. [9] discussed a Multi-item inventory model with 
probabilistic price dependent demand and imprecise goal and constraints. The author [10]discussed about the stochastic uniform inventory model with varying cost and a constraint on the holding cost by considering the average inventory at any time ' $t$ '.[11] studied a continuous review model with lost sales case, varying order cost, a restriction on holding cost and also lead time demand is assumed as normal distribution. [12] studied a probabilistic inventory model for deteriorating items with ramp type demand rate under inflation. An attempt is made to extend the paper [10] for a two warehouse by taking constant holding cost and also varying the number of items stored in OW and RW.

\section{Assumptions}

- System is single period and no lead time.

- The number of units to be purchase for inventory at the beginning of the period ' $\mathrm{S}$ ' and stock level decreases at a uniform rate over a demand.

- The demand ' $\mathrm{x}$ ' during that period is a continuous random variable with known pdf.

- There is no setup cost (order cost).

\section{Notations}

- $\mathrm{f}(\mathrm{x})=$ The pdf of the demand ' $\mathrm{x}$ ' during the period.

- $\mathrm{E}[\mathrm{x}]=$ Expected value of $\mathrm{x}$.

- $\mathrm{F}(\mathrm{x})=$ Cumulative distribution function of $\mathrm{f}(\mathrm{x})$.

- $\mathrm{C}=$ Purchase cost of unit item.

- $\mathrm{C}_{\mathrm{OW}}=$ Holding Cost in Own Warehouse.

- $\mathrm{C}_{\mathrm{RW}}=$ Holding Cost in Rented Warehouse.

- $\mathrm{C}_{\mathrm{s}}=$ Shortage Cost.

- $\mathrm{K}=$ Limitation of the expected holding cost for the period.

- $\mathrm{E}[\mathrm{PC}]=$ Expected purchase cost.

- $\mathrm{E}[\mathrm{HC}]=$ Expected holding cost.

- $\mathrm{E}[\mathrm{SC}]=$ Expected shortage cost.

- $\mathrm{E}[\mathrm{TC}]=$ Expected total cost.

\section{Model Description}

Out of ' $S$ ' units purchased, ' $W$ ' units are stored in OW and the remaining S-W are stored in RW. Depending on the amount of demand $x$ and the Stock purchased ' $S$ ' , the inventory level is either positive(holding) or negative(shortage). So three cases araises which are shown in the figure. 1 . Let $\mathrm{H}(\mathrm{S}, \mathrm{W}, \mathrm{x})=\mathrm{The}$ random variable that denotes the inventory position at the end of the period, and $S(S, x)=$ The random variable that denotes

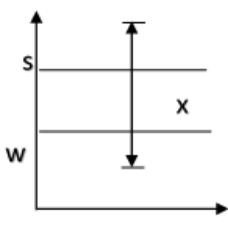

Fig 1(a)

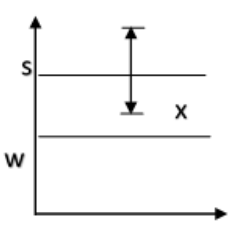

Fig 1(b)

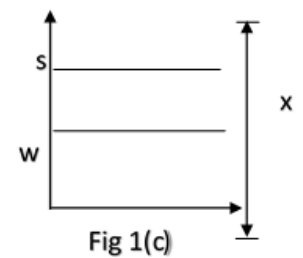

Fig 1(c)
Figure 1

the shortage quantity at the end of the period. From the Fig1 it is clear that

$$
H(S, W, x)= \begin{cases}W-x / 2 & \text { for } 0<x \leq W \\ S-W-x / 2 & \text { for } W<x<S \\ S^{2} / 2 x & \text { for } S>W\end{cases}
$$

and

$$
\begin{aligned}
& S(S, x)= \begin{cases}0 & \text { for } 0<x \leq S \\
(x-S)^{2} / 2 x & \text { for } x>S\end{cases} \\
& E[P C]=C \int_{0}^{\infty} S f(x) d x=C S
\end{aligned}
$$

$$
\begin{array}{r}
E[H C]=C_{\mathrm{OW}} \int_{0}^{W}(W-x / 2) f(x) d x \\
+C_{\mathrm{RW}} \int_{W}^{S}(S-W-x / 2) f(x) d x \\
+C_{\mathrm{OW}} \int_{S}^{\infty}\left(S^{2} / 2 x\right) f(x) d x \\
E[S C]=C_{\mathrm{s}} \int_{S}^{\infty}\left((x-S)^{2} / 2 x\right) f(x) d x \\
E[T C]=(5.1)+(5.2)+(5.3)
\end{array}
$$

Using the Lagranges method of multipliers for minimizing the total expected cost (5.4) subject to the condition that $\mathrm{E}[\mathrm{HC}] \leq K$. So defining new a function $L(S, W, \lambda)=E[T C]+$ $\lambda(E(H C)-K)$ the optimal value $\mathrm{S}^{\star}$ and $\mathrm{W}^{\star}$ can be found by solving the equations

$$
\frac{\partial L}{\partial S}=0
$$

and

$$
\frac{\partial L}{\partial W}=0
$$

which gives

$$
\begin{array}{r}
C+(1+\lambda) C_{\mathrm{RW}}\left[\int_{W}^{S} f(x) d x+(S / 2-W)(f(S)]\right. \\
+(1+\lambda) C_{\mathrm{OW}}\left[\int_{S}^{\infty}(S / x) f(x) d x-(S / 2) f(S)\right] \\
+C_{\mathrm{s}} \int_{S}^{\infty}((x-S) / x) f(x) d x=0
\end{array}
$$




$$
\begin{gathered}
C_{\mathrm{OW}} \int_{0}^{W} f(x) d x \\
+(W / 2) f(W)-C_{\mathrm{RW}} \int_{W}^{S} f(x) d x \\
+(S-W / 2) f(W)=0 \\
C+(1+\lambda) C_{\mathrm{RW}}[F(S)-F(W)]+(S / 2-W)(f(S)] \\
+(1+\lambda) C_{\mathrm{OW}}\left[\int_{S}^{\infty}(S / x) f(x) d x-(S / 2) f(S)\right] \\
+C_{\mathrm{s}}\left[1-F(S)-S \int_{S}^{\infty} f(x) / x d x=0\right. \\
C_{\mathrm{OW}}[F(W)+(W / 2) f(W)] \\
-C_{\mathrm{RW}}[F(W)-F(S)+(S-w / 2) f(W)=0
\end{gathered}
$$

Assuming that the demand during the period follows the uniform distribution $\mathrm{f}(\mathrm{x})=1 / \mathrm{b} ; \mathrm{E}(\mathrm{x})=\mathrm{b} / 2 ; \mathrm{F}(\mathrm{S})=\mathrm{S} / \mathrm{b} ; \mathrm{F}(\mathrm{w})=\mathrm{W} / \mathrm{b}$; when $\int_{S}^{\infty}(f(x) / x) d x=(1 / b) \ln (b / S)$ is substituted in equations[5.7] and [5.8] we get

$$
\begin{gathered}
C+(1+\lambda) C_{\mathrm{RW}}[(S / b)]-(W / b) \\
+(S / 2-W)((1 / b)]+(1+\lambda) C_{\mathrm{OW}} / b[\ln (b / s)-(S / 2)](5.9) \\
+C_{\mathrm{s}}[1-(S / b)-(S / b) \ln (b / s)=0 \\
C_{\mathrm{OW}}[(3 W / 2 b)]-C_{\mathrm{RW}}[(W / b)-(S / b)+(S-3 W / 2) / b]=0
\end{gathered}
$$

from the equation [5.10]

$$
W=\frac{4 S C_{\mathrm{RW}}}{3 C_{\mathrm{OW}}+5 C_{\mathrm{RW}}}
$$

and substituting [5.11] in [5.9] and the obtained equation can be solved by Newton Raphson's Method to get minimum value of $S$

\section{Example}

Considering the following single period with the parameters $\mathrm{C}=3, \mathrm{C}_{\mathrm{RW}}=7, \mathrm{C}_{\mathrm{OW}}=5, \mathrm{C}_{\mathrm{s}}=5, \mathrm{~K}=40$ and $\mathrm{b}=25$ the optimal number of quantity to be purchased and stored in both $\mathrm{OW}(\mathrm{W})$ as well as in $\mathrm{RW}(\mathrm{Z})$ and also the expected holding cost $(\mathrm{E}[\mathrm{HC}])$ and expected total cost $(\mathrm{E}[\mathrm{TC}])$ are also calculated and tabulated in the table 1

From the table 1 it is observed that as the value of $\mathrm{K}$ (the constraint on holding cost) increases the expected holding cost increases and the expected total cost decreases at the same time. So the less number of units have been purchased.
Table 1. The optimal solutions for different values of $\lambda$

\begin{tabular}{|c|c|c|c|c|c|}
\hline$\lambda$ & $\mathrm{S}$ & $\mathrm{W}$ & $\mathrm{Z}=\mathrm{S}-\mathrm{W}$ & $\mathrm{E}[\mathrm{HC}]$ & $\mathrm{E}[\mathrm{TC}]$ \\
\hline 0 & 36.52 & 20.45 & 16.07 & 20.39 & 126.28 \\
\hline 1 & 32.13 & 17.99 & 14.14 & 29.01 & 124.50 \\
\hline 2 & 30.27 & 16.95 & 13.32 & 31.22 & 121.66 \\
\hline 3 & 29.25 & 16.38 & 12.87 & 32.07 & 119.65 \\
\hline 4 & 28.62 & 16.02 & 12.6 & 32.50 & 118.22 \\
\hline 5 & 28.17 & 15.77 & 12.4 & 32.74 & 117.18 \\
\hline 6 & 27.85 & 15.59 & 12.26 & 32.88 & 116.39 \\
\hline
\end{tabular}

\section{Conclusions}

An optimal solution for a single period with uniform demand and a constraint on the holding cost is derived. An expression is derived to evaluate the optimum quantity that can be purchased and the optimum quantity that can be stored in OW as well as in RW. Total expected cost is also evaluated. Above numerical example illustrates that by varying the number of units stored in OW the expected total cost reduces.

\section{References}

[1] KARTEEK nbspPONNURU RAMALINGA et al. Deterministic and probabilistic models in inventory control. International Journal of Engineering Development and Research (IJEDR), 2(3):3100-3105, 2014.

[2] Jie Min, Yong-Wu Zhou, and Ju Zhao. An inventory model for deteriorating items under stock-dependent demand and two-level trade credit. Applied Mathematical Modelling, 34(11):3273-3285, 2010.

[3] M Madhavilata, K Srinivasa Rao, and V Ravindranath. An order level inventory model under 12-system with exponentially increasing demand. International J. of Engineering Research and Applications, 1 (4), pages 17441750, 2011.

[4] Chandra K Jaggi, KK Aggarwal, and Priyanka Verma. Two-warehouse inventory model for deteriorating items when demand is price sensitive. International Journal of Operational Research, 7(4):530-551, 2010.

[5] Ajay Singh Yadav, Sanjai Sharma, and Anupam Swami. Two warehouse inventory model with ramp type demand and partial backordering for weibull distribution deterioration. International Journal of Computer Applications, 140(4), 2016.

[6] SP Singh and VK Sehgal. An eoq inventory model for weibull distributed deteriorating items with power demand pattern and shortages. JP Journal of Mathematical Sciences, 1(2):99-110, 2011.

[7] Deepa Khurana. Two warehouse inventory model for deteriorating items with time dependent demand under inflation. International Journal of Computer Applications, 114(7), 2015.

[8] TPM Pakkala and KK Achary. A two-warehouse probabilistic order-level inventory model for deteriorating 
items. Journal of the Operational Research Society, 42(12):1117-1122, 1991.

[9] S Kar, T Roy, and M Maiti. Multi-item inventory model with probabilistic price dependent demand and imprecise goal and constraints. Yugoslav journal of operations research, 11(1):93-103, 2001.

[10] AF Hala and ME EI-Saadani. Constrained single period stochastic uniform inventory model with continuous distributions of demand and varying holding cost. Journal of Mathematics and Statistics, 2(1):334-338, 2006.

[11] A Fergany, FE Wakeel, et al. Constrained probabilistic lost sales inventory system with normal distribution and varying order cost. Journal of Mathematics and Statistics, 2(1):363-366, 2006.

[12] Sushil Kumar and US Rajput. A probabilistic inventory model for deteriorating items with ramp type demand rate under inflation. American Journal of Operational Research, 6(1):16-31, 2016.

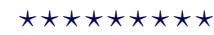

ISSN(P):2319-3786

Malaya Journal of Matematik

ISSN(O):2321 - 5666

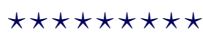

